\title{
PERSPECTIVES
}

Invited article

Original version | DOI: http://dx.doi.org/10.1590/So034-759020210509

\section{METHODOLOGICAL APPROACHES TO TACKLING FOOD WASTE: MOVING THE AGENDA FORWARD}

\author{
Luciana Marques Vieira1 | luciana.vieira@fgv.br | ORCID: 0000-0002-3996-0901 \\ Marcia Dutra de Barcellos² | marcia.barcellos@ufrgs.br | ORCID: 0000-0002-4311-2921

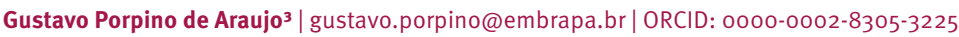 \\ Daniele Eckert Matzembacher4 | daniele.eckert@ufrgs.br | ORCID: 0000-0002-5781-1555 \\ ${ }^{1}$ Fundação Getulio Vargas, Escola de Administração de Empresas de São Paulo, SP, Brazil \\ ${ }^{2}$ Universidade Federal do Rio Grande do Sul, Escola de Administração, Porto Alegre, RS, Brazil \\ 3Empresa Brasileira de Pesquisa Agropecuária, Embrapa Alimentos e Territórios, Maceió, AL, Brazil \\ ${ }^{4}$ Universidade Federal do Rio Grande do Sul, Escola de Administração, Porto Alegre, RS, Brazil
}

\section{INTRODUCTION}

COVID 19 disrupted food supply chains worldwide. Existing problems, such as food and nutrition insecurity, increased exponentially. It has become imperative to move to a more sustainable and equitable food system. In this sense, the challenge in researching food losses and waste (FLW) and proposing solutions mobilizes transdisciplinary approaches and processes to transform food supply chains in an effective manner. Understanding how much food we produce and consume is no easy task. So many different geographical, cultural and societal contexts and levels of economic development and urbanization result in quantitative and qualitative limitations.

According to Corrado et al. (2019), accounting for food waste is a central element in designing an FLW policy and the interventions that are proposed. The methodology adopted when accounting for waste is key to monitoring the progress made towards reducing targets. There is no best way of tackling food losses and waste, but many relevant and rigorous attempts are made using different methods. Some of them are discussed in this paper, which suggests a methodological agenda for business and management researchers who are interested in this challenge.

\section{BACKGROUND LITERATURE}

Food loss and waste can be defined as a decrease in the quantity or quality of food along the food supply chain. Empirically, it considers food losses as occurring along the whole food supply chain from harvest/slaughter/catch right up to, but not including the retail level. Food waste, on the other hand, occurs at the retail and consumption levels (Food and Agriculture Organization of the United Nations [FAO], 2019, p. 14). 
The causes of FLW are connected across food supply chains, from primary production to final consumption (Bilska, Wrzosek, Kołożyn-Krajewska, \& Krajewski, 2016; Canali et al., 2017). Consequently, research into FLW has emerged as a priority issue for both academics and practitioners. Much of the research, however, focuses on just one activity in the food supply chain, not on the interactions between the different stakeholders, or on the complex phenomenon of FLW. FLW is a transdisciplinary topic, but a large area of interest in business and management comes from marketing (the majority of studies that analyze consumer food waste) and operations management literature. These two units of analysis and the methodological trends used in studying them are discussed below.

\section{Consumer side}

Different methods are used for measuring consumer food waste, such as self-report surveys, food waste diaries, photo coding, and waste composition analysis (Quested, Palmer, Moreno, McDermott, \& Schumacher, 2020). Given the need to standardize quantification across different countries as a means of tracking achievement of its Sustainable Development Goal 12.3, the United Nations Environment Programme suggests using waste composition analysis, and direct measurement in households via scales, or diaries. Diaries are useful for food that goes down the sewer, is composted at home, or is fed to animals (UNEP, 2021). Interviews and surveys, a common method in academic studies, should not be used in isolation, because of a large element of underestimation (Herpen, Lans, Holthuysen, Nijenhuis-de Vries, \& Quested, 2019). Matzembacher, Brancoli, Maia and Eriksson (2020) identified a discrepancy between stated and actual behavior in relation to consumer food waste. This involves methodological questions, with a series of studies being based on consumer perceptions and reports. Therefore, interviews and surveys should be combined in a mixed-method approach.

In a developing world context, waste composition analysis is challenging because organic and inorganic waste is not sorted in certain regions. Furthermore, direct measurement at home requires considerable investment and the need to train participants to sort the waste in order to quantify it accurately. To overcome this drawback, a potential solution is to utilize bulk sampling with randomized grab sub-sampling to cover a representative sample of the municipal waste collected, as undertaken by Oelofse, Muswema and Ramukhwatho (2018) who quantified household food waste in South Africa.

The degree of underestimation of food waste in diaries ranges from $7 \%$ to $40 \%$, compared to waste composition analysis, according to Quested et al. (2020). Compared to surveys, however, diaries perform better in estimating consumer food waste (Giordano, Alboni, \& Falasconi, 2019). As such, a feasible method by which developing countries can measure food waste would be to rely on mixed-method approaches, which combine diaries, especially those using digital platforms, with photo uploads to double-check the amount of waste informed, and analysis of waste composition in those areas in which organic waste is collected separately.

In a national quantification of consumer food waste in Brazil, which was part of a project funded by the Sector Dialogues European Union- Brazil, diaries were used via a mobile platform on which consumers could indicate via a simple form indicating portions which food was wasted, and the amounts. The app could also be used to upload photos to compare if the foods and amounts were precisely informed (Porpino, Lourenço, Araújo, \& Bastos, 2018). Van Herpen et al. (2019) consider that photo coding has the potential for improving the accuracy of measurements, but is time consuming and may not be feasible for large samples. 
Food waste quantification is a baseline for fostering science-based urban food policies, but the value of qualitative approaches for understanding the root causes of consumer food waste better should not be underestimated in academic studies. Apart from the theoretical contributions, qualitative methods are useful, for instance, for guiding the development of communication campaigns aimed at changing behavior.

At-home observations combined with laddering interviews are a rich qualitative method for uncovering food waste behaviors that are not easily identified in self-reports, such as surveys. However, the application of these qualitative approaches requires well-trained researchers, and the ability to perform interviews without influencing respondents to give the desired answers. As such, laddering techniques, in which respondents are exposed to "why" type questions, are important for obtaining a deeper understanding of consumer behavior (Veludo-de-Oliveira, Ikeda, \& Campomar, 2006).

In terms of theoretical contributions, grounded theory can also be applied for identifying those behaviors that result in food waste. Grounded theory coding (Corbin \& Strauss, 2015), as used by Porpino, Wansink, and Parente (2016) to investigate food waste in lower-middle income families, and by Papargyropoulou et al. (2016) to study food waste in the hospitality sector, is suitable for generating theoretical contributions and providing insights in policy-oriented strategies, such as nutritional education and sustainable consumption campaigns. It is also used for identifying relevant concepts for framing messages aimed at influencing food choices in retail settings or food pantries, for instance.

Stangherlin, Barcellos and Basso (2018) recently studied the effect of social norms on driving suboptimal food consumption in Brazil. Social norms represent the common and accepted behavior in a specific situation that directly affects attitudes, intentions, preferences, and choices (Cialdini, Reno, \& Kallgren, 1990). Consumers prefer not to buy fruit and vegetables with an unusual appearance, or products whose packaging is damaged, or those that are close to their expiry date; these are usually called suboptimal food products (Aschemann-Witzel, Hooge, Amani, Bech-Larsen, \& Oostindjer, 2015; Hooge et al., 2017; Loebnitz \& Grunert, 2015; Loebnitz, Schuitema, \& Grunert, 2015). This pattern of behavior and the consequent demand for "cosmetically perfect" food contributes to high levels of food waste (Godfray et al., 2010; Gustavsson, Cederberg, Sonesson, Otterdijk, \& Meybeck, 2011) and interventions aimed at encouraging the purchase of suboptimal food. The study also tested if awareness of the food waste problem is the underlying mechanism in the relationship between social norms and intention to buy suboptimal food. Results show that appeals that employ social norms have a positive effect on the intention to purchase products with an unusual appearance, or products with damaged packaging. Awareness of the food waste problem also mediates the effect of social norms on the intention to purchase a product with an unusual appearance. In theoretical terms, the study analyzed the effect of stimulus in suboptimal food consumption by applying the theory of normative influences. Practical implications indicate strategies for increasing the acceptance of suboptimal food products. The decision making of consumers can be positively influenced if appropriate messages are provided by retailers and food marketers. A suggestion would be to develop interventions at the point-of-purchase that show the sensory and organoleptic characteristics of the products. Nudge marketing, consumer education campaigns, and the use of trustworthy celebrities to endorse consumption are strategies that could lead to increasing intentions to consume suboptimal food products. Consumer-level change, therefore, must be systemically supported by education and different initiatives that can lead to a substantial decline in waste food going to landfill sites, thereby saving public and private resources, and contributing to achieving the SDGs. 


\section{Supply chain side}

Morgan, Hawkes, Dangour and Lock (2019) characterize food and nutrition value chain studies to identify opportunities for reducing waste throughout the chain. While most of the time the supply chain framework overlaps the value chain, the former emphasizes the logistics of product flow. Governance mode and the extent of the supply chain are factors that influence FLW.

Studies focusing on supply chain cases take a more systemic approach in that they try to understand how interorganizational relationships can mitigate FLW. There are two main theories for understanding supply chain governance. Transaction cost economics (TCE) is the theoretical analysis of relationships between supply chain agents that enables the analysis of governance to be split into three types: hierarchy, market and hybrid. A hybrid or collaborative relationship between buyer and supplier can reduce the costs involved in the transaction (Williamson, 2000). Relationships are often not purely collaborative or opportunistic, however, so TCE can be used in conjunction with other approaches.

The second theoretical background is the relational view (RV), which can be considered an extension of the resource-based view (RBV). While RBV focuses on internal resources of the company, RV suggests that idiosyncratic relationships exist between organizations. These theories can lead to a complementary perspective of formal and informal governance mechanisms in a supply chain (Cislaghi, Wegner, \& Vieira, 2021). The main assumption of these theories is that collaborative relationships within the supply chain can have an influence on awareness of food waste and, consequently, reduce it. In this perspective, food waste is an economic cost related to waste management practices.

These theoretical approaches support case studies that have a firm or a dyad as the unit of analysis, such as Mena, Adenso-Diaz and Yurt (2011), who adopted a buyer-supplier approach when gathering data in two countries. This research extended to include Mena, Terry, Williams and Ellram (2014) with the aim of understanding the main causes of FLW in the two product categories with highest demand in the UK grocery sector. It used mixed methods, such as the use of quantitative data to assess the impact of waste. It then carried out multiple case studies using an inductive and theory building approach with open questions. Cross-checking the case studies puts forward propositions aimed at making theoretical contributions to the natural-resource-based view (NRBV). Richards, Hurst, Messner and O'Connor (2021) expanded the unit of analysis to include the whole horticultural supply chain in an attempt to identify existing paradoxes, and they used semi-structured and open questions and secondary data to do so. This study tries to take a more holistic view and avoid pointing out where the food is wasted, to indicate how and why it is wasted. Matzembacher, Vieira and Barcellos (2021) argue that a multistakeholder perspective is needed, and that not just the supply agents should be investigated, but other intervening stakeholders as well, such as NGOs, public agencies, academia, etc.

Within this context, SCM has been evolving from being an isolated investigation perspective dealing with the interfaces between environmental and economic topics, to a vision of corporate social responsibility applied to the supply chain. These studies (Matzembacher et al., 2021; Mena et al., 2014; Richards et al., 2021) exemplify an advance in the research, from focusing on a single point, or on one relationship within the supply chain, to a more holistic analysis. While there are several limitations when it comes to measuring or generalizing in this kind of research, it engages multiple stakeholders in the task of tackling FLW. The use of a multistakeholder approach brings research closer to the real world. In many real cases, reducing FLW to a 
single point (production, processing, distribution) results in transferring the waste to the next link in the supply chain; it does not tackle the problem.

When seeking to understand more of the data on the quantification and impact that FLW has, life cycle assessment (LCA) is a very relevant methodology to use. LCA is a systematic approach for assessing environmental impact throughout a product's or a process's life, from extracting the raw material to disposal. Eriksson and Spångberg (2017) conducted some interesting research in this regard. The LCA methodology is widely used for examining environmental impacts associated with FLW management. This is important for decision-making processes and when preparing public policy. LCA analyses can also incorporate a holistic analysis. As Omolayo, Feingold, Neff and Romeiko (2021) propose, rather than focusing just on one or a few activities, it is interesting to include all stages of the food supply chain within the system boundary to capture in more detail the influence of the whole process on the interventions, and to identify key leverage points within the food supply chain for effectively reducing the environmental impacts of FLW.

\section{FOOD FOR THOUGHT}

As FLW research is still divided between consumers and the supply chain, which are analyzed separately, it should move towards adopting an integrated approach that positions the consumer in the context of the supply chain. The challenge is to develop theories and methods that allow this interface between marketing and operations management, with mix methods and units of analysis.

The role of applied research in tackling FLW is key to providing effective solutions. Evidence-based policies (Oliver \& Boaz, 2019) and evidence-based management (Pfeffer \& Sutton, 2006) can provide space for interventions in the short term and a consistent change in behavior in the long term. Researchers are challenged to transform research findings into policies or management practices in order to make a positive impact on reducing FLW. Policies might include a good mix of regulatory and voluntary measures, while economic and financial measures are limited. Managerial tools and solutions are required to support the implementation of voluntary measures and the achievement of the SDGs with regard to reducing FLW.

A holistic approach can expand the unit of analysis to include multiple stakeholders and the use of mixed methods, such as undertaking mini-surveys and using techniques, such as social network analysis to understand which stakeholder influences another when it comes to changing behaviors. LCA analytics can also seek to provide a more general picture of the entire supply chain, thereby seeking a more holistic view.

A future research agenda could consider moving away from the "unit" view, whether that be adopting singleactor analysis of the supply chain/consumer level, or using a single methodology. FLW is a complex problem, interconnected at the supply and consumption levels, in which the action of one agent has an impact on others. Each methodology has its strengths and weaknesses when used alone. Given this complexity, it is suggested that a more holistic approach be integrated into research agendas, either by way of multi-stakeholder analysis, or by combining methodologies in order to have a deeper and more concise vision of the FLW problem, and achieve a more integrated impact with the solutions proposed. 


\section{REFERENCES}

Aschemann-Witzel, J., Hooge, I. de, Amani, P., Bech-Larsen, T., \& Oostindjer, M. (2015). Consumer-related food waste: Causes and potential for action. Sustainability, 7, 6457-6477. http:// doi.org/10.339o/su7066457

Bilska, B., Wrzosek, M., Kołożyn-Krajewska, D., \& Krajewski, K. (Julho 2016). Risk of food losses and potential of food recovery for social purposes. Waste Management, 52, 269277. doi: 10.1016/j.wasman.2016.03.035

Canali, M., Amani, P., Aramyan, L., Gheoldus, M., Moates, G., Östergren, K., ... \& Vittuari, M. (2017). Food waste drivers in Europe, from identification to possible interventions. Sustainability, 9(1), 37. doi:10.3390/sug010037

Cialdini, R. B., Reno, R. R.., \& Kallgren, C. A. (1990). A focus theory of normative conduct: Recycling the concept of norms to reduce littering in public places. Journal of Personality and Social Psychology, 58, 1015. doi: 10.1037/00223514.58.6.1015

Cislaghi, T. P., Wegner, D., \& Vieira, L. M. (June, 2021). How do governance and relational rents evolve during the maturity stages of supply chains? Supply Chain Management, in-press. doi: 10.1108/SCM-07-2020-0296

Corbin, J., \& Strauss, A. (2015). Basics of qualitative research: Techniques and procedures for developing grounded theory (4th ed.). Thousand Oaks, USA: Sage.

Corrado, S., Caldeira, C., Eriksson, M., Hanssen, O. J., Hauser, H. E., Holsteijn, F. van, ... \& Sala, S. (March, 2019). Food waste accounting methodologies: Challenges, opportunities, and further advancements. Global Food Security, 20, 93-100. doi: 10.1016/j.gfs.2019.01.002

Eriksson, M., \& Spångberg, J. (February, 2017). Carbon footprint and energy use of food waste management options for fresh fruit and vegetables from supermarkets. Waste Management, 60, 786-799. doi: 10.1016/j.wasman.2017.01.008

Food and Agriculture Organization of the United Nations. (2019). The state of food and agriculture 2019. Moving forward on food loss and waste reduction. Rome, Italy.

Giordano, C., Alboni, F., \& Falasconi, L. (2019). Quantities, determinants, and awareness of households' food waste in Italy: A comparison between diary and questionnaires quantities. Sustainability, 11(12), 3381. doi: 10.3390/ su11123381

Godfray, H. C. J., Beddington, J. R., Crute, I. R., Haddad, L., Lawrence, D., Muir, J. F., \& Toulmin, C. (2010). Food security: the challenge of feeding 9 billion people. Science, 327, 812818. doi: $10.1126 /$ science. 1185383

Gustavsson, J., Cederberg, C., Sonesson, U., Otterdijk, R. van, \& Meybeck, A. (2011). Global food losses and food waste: Extent causes and prevention. Rome, Italy. Food and Agriculture Organization (FAO) of the United Nations.
Herpen, E. Van, Lans, I. van der, Holthuysen, N., Nijenhuis-de Vries, M., \& Quested, T. (2019). Comparing wasted apples and oranges: An assessment of methods to measure household food waste. Waste Management, 88, 71-84. doi: 10.1016/j. wasman.2019.03.013

Hooge, I. E. de, Oostindjer, M., Aschemann-Witzel, J., Normann, A., Loose, S. M., \& Almli, V. L. (2017). This apple is too ugly for me! Consumer preferences for suboptimal food products in the supermarket and at home. Food Quality and Preference, 56, 80-92. doi: 10.1016/j.foodqual.2016.09.012

Loebnitz, N., \& Grunert, K. G. (2015). The effect of food shape abnormality on purchase intentions in China. Food Quality and Preference, 40, 24-30. doi: 0.1016/j.foodqual.2014.08.005

Loebnitz, N., Schuitema, G., \& Grunert, K. G. (2015). Who buys oddly shaped food and why? Impacts of food shape abnormality and organic labelling on purchase intentions. Psychology \& Marketing, 32, 408-421. doi: 10.1002/mar.20788

Matzembacher, D. E., Brancoli, P., Maia, L. M., \& Eriksson, M. (2020). Consumer's food waste in different restaurants configuration: A comparison between different levels of incentive and interaction. Waste Management, 114, 263-273. doi: 10.1016/j.wasman.2020.07.014

Matzembacher, D. E., Vieira, L. M., \& Barcellos, M. D. de. (2021). An analysis of multi-stakeholder initiatives to reduce food loss and waste in an emerging country-Brazil. Industrial Marketing Management, 93, 591-604. doi: 10.1016/j. indmarman.2020.08.016

Mena, C., Adenso-Diaz, B.. \& Yurt, O. (2011). The causes of food waste in the supplier-retailer interface: Evidences from the UK and Spain. Resources, Conservation and Recycling, 55(6), 648-658. doi: 10.1016/j.resconrec.2010.09.006

Mena, C., Terry, L. A., Williams, A., \& Ellram, L. (2014). Causes of waste across multi-tier supply networks: Cases in the UK food sector. International Journal of Production Economics, 152, 144-158. doi: 10.1016/j.ijpe.2014.03.012

Morgan, E., Hawkes, C., Dangour, A., \& Lock, K. (2019). Analyzing food value chains for nutrition goals. Journal of Hunger \& Environmental Nutrition, 14(4), 447-465. doi: 10.1080/19320248.2018.1434106

Oelofse, S., Muswema, A., \& Ramukhwatho, F. (2018). Household food waste disposal in South Africa: A case study of Johannesburg and Ekurhuleni. South African Journal of Science, 114(5/6). doi: 10.17159/sajs.2018/20170284

Oliver, K., \& Boaz, A. (2019).Transforming evidence for policy and practice: Creating space for new conversations. Palgrave Communication, 5, 60. doi: 10.1057/s41599-019-0

Omolayo, Y., Feingold, B. J., Neff, R. A., \& Romeiko, X. X. (January, 2021). Life cycle assessment of food loss and waste in the food supply chain. Resources, Conservation and Recycling, 164, 105119. doi: 10.1016/j.resconrec.2020.105119 
Papargyropoulou, E., Wright, N., \& Lozano, R., Steinberger, J., Padfield, R., \& Ujang, Z. (Março, 2016). Conceptual framework for the study of food waste generation and prevention in the hospitality sector. Waste Management, 49, 326-336. doi: 10.1016/j.wasman.2016.01.017

Pfeffer, J., \& Sutton, R. I. (2006). Evidence based management. Harvard Business Review, 84(1), 62. Retrieved from https:// hbr.org/2006/01/evidence-based-management

Porpino, G., Lourenço, C. E., Araújo, C. M., \& Bastos, A. (2018). Intercâmbio Brasil: União Europeia sobre desperdício de alimentos. Brasília, DF: Diálogos Setoriais União Europeia - Brasil. Retrieved from http://www.sectordialogues.org/documentos

Porpino, G., Wansink, B., \& Parente, J. (2016). Wasted positive intentions: The role of affection and abundance on household food waste. Journal of Food Products Marketing, 22(7), 733751. doi: 10.1080/10454446.2015.1121433

Quested, T., Palmer, G., Moreno, L., McDermott, C., \& Schumacher, K. (July, 2020). Comparing diaries and waste compositional analysis for measuring food waste in the home. Journal of Cleaner Production, 262, 121263. doi: 10.1016/j.jclepro.2020.121263
Richards, C., Hurst, B., Messner, R., \& O'Connor, G. (2021). The paradoxes of food waste reduction in the horticultural supply chain. Industrial Marketing Management, 93, 482-491. doi: 10.1016/j.indmarman.2020.12.002

Stangherlin, I. C., Barcellos, M.D. De, \& Basso, K. (2018). The impact of social norms on suboptimal food consumption: A solution for food waste. Journal of International Food \& Agribusiness Marketing, 32(1), 30-53. doi: $10.1080 / 08974438.2018 .1533511$

United Nations Environment Programme. (2021). Food Waste Index Report 2021. Nairobi: Quênia.

Veludo-de-Oliveira, T. M., Akemi Ikeda, A., \& Campomar, M. C. (2006), Laddering in the practice of marketing research: Barriers and solutions. Qualitative Market Research, 9(3), 297-306. doi: 10.1108/13522750610671707

Williamson, O. E. (2000). The new institutional economics: Taking stock, looking ahead. Journal of Economic Literature, 38(3), 595-613. Retrieved from http://www.jstor.org/stable/2565421

\section{AUTHOR'S CONTRIBUTION}

Luciana Marques Vieira, Marcia Dutra de Barcellos, Gustavo Porpino de Araujo and Daniele Eckert Matzembacher worked on the conceptualization and theoretical-methodological approach. The theoretical review was conducted by Luciana Marques Vieira, Marcia Dutra de Barcellos,Gustavo Porpino de Araujo e Daniele Eckert Matzembacher Data collection was coordinated by Luciana Marques Vieira, Marcia Dutra de Barcellos,Gustavo Porpino de Araujo e Daniele Eckert Matzembacher Data analysis included Luciana Marques Vieira, Marcia Dutra de Barcellos,Gustavo Porpino de Araujo e Daniele Eckert Matzembacher. All authors worked together in the writing and final revision of the manuscript. 